\title{
The Ventilated Building System
}

\author{
Birger E. Wasenius ${ }^{1}$ \\ ${ }^{1}$ Palikka Oy, Finland
}

\begin{abstract}
The accelerating climate change greatly streches the demands of sustainable methods of building safe and sound low energy buildings. Because of the increasingly moist climate wooden constructions are risky, thus moisture safe stone constructions are the right solution. The Palikka engineers have foreseen this development already 50 years ago, thus developing the Palikka ${ }^{\circledR}$ Original Building System with built-in ventilation properties.
\end{abstract}

\section{Background}

After the oil crisis in the 1970s, when the (heating) oil prices rose from less than $\$ 1$ per barrel to more than $\$ 20$, new innovative and more energy efficient building solutions were needed more than before.

A Finnish invention, the Palikka ${ }^{\circledR}$ Building Block was the simple low-cost solution for the construction of high-quality energy saving buildings. When introduced in the 1970s its thermal insulation was twice as good as the best products on the market.

Being 50 times more lightweight, ten times stronger stone walled buildings could be erected 3-4 times faster than with any traditional systems. Eg the thermowalls of a $100 \mathrm{~m} 2$ stone structure building can be erected in just a week by one (wo)man. The sturdy steel reinforced sustainable insulated concrete walls stand for 500 years.

The buildings are safe and nontoxic without HBCD or other harmful additives. The fire classification is REI60 according to firetests made. The buildings are radon safe when Radonix ${ }^{\circledR}$ safety foil is used. The sound insulation is good and the acoustics echofree.

In addition to all its other benefits, only the Palikka Orignal Building System has a built-in naturally (= without separate, mechanical machinery) functioning Ventilation System, which keeps the constructions dry and sound - no moisture or mildew problems in or on the houses.

In this paper is told how the built-in naturally functioning Ventilation System can be used also for the preheating and precooling of the air in the buildings. The quality of the breathing air is classified M1.

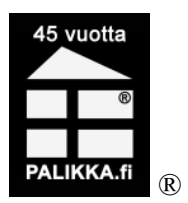

The internationally awarded Palikka inventions have been granted patents and registered designs in several countries. Palikka ${ }^{\circledR}$ is a registered and protected trademark in all EU countries.

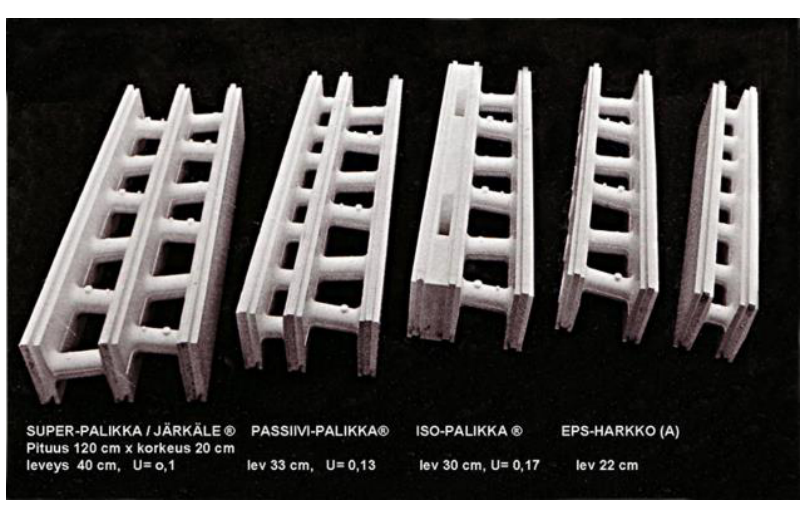

Fig. 1. Palikka Original Building Blocks. The thermal insulation and ventilation can be chosen as You wish.

The Palikka measures L $120 \mathrm{~cm}$ x H $20 \mathrm{~cm}$ x W varies 22-40 cm depending on insulation need, and the low weight is about $1 \mathrm{~kg}$ each.

The versatile Block (Fig. 1)can be used for all kinds of constructions. With just one type of Blocks all technical constructions and architectional shapes can easily be erected (the rounded forms are genuinely curved, not angular).

\footnotetext{
* Corresponding author: palikka@palikka.eu
} 

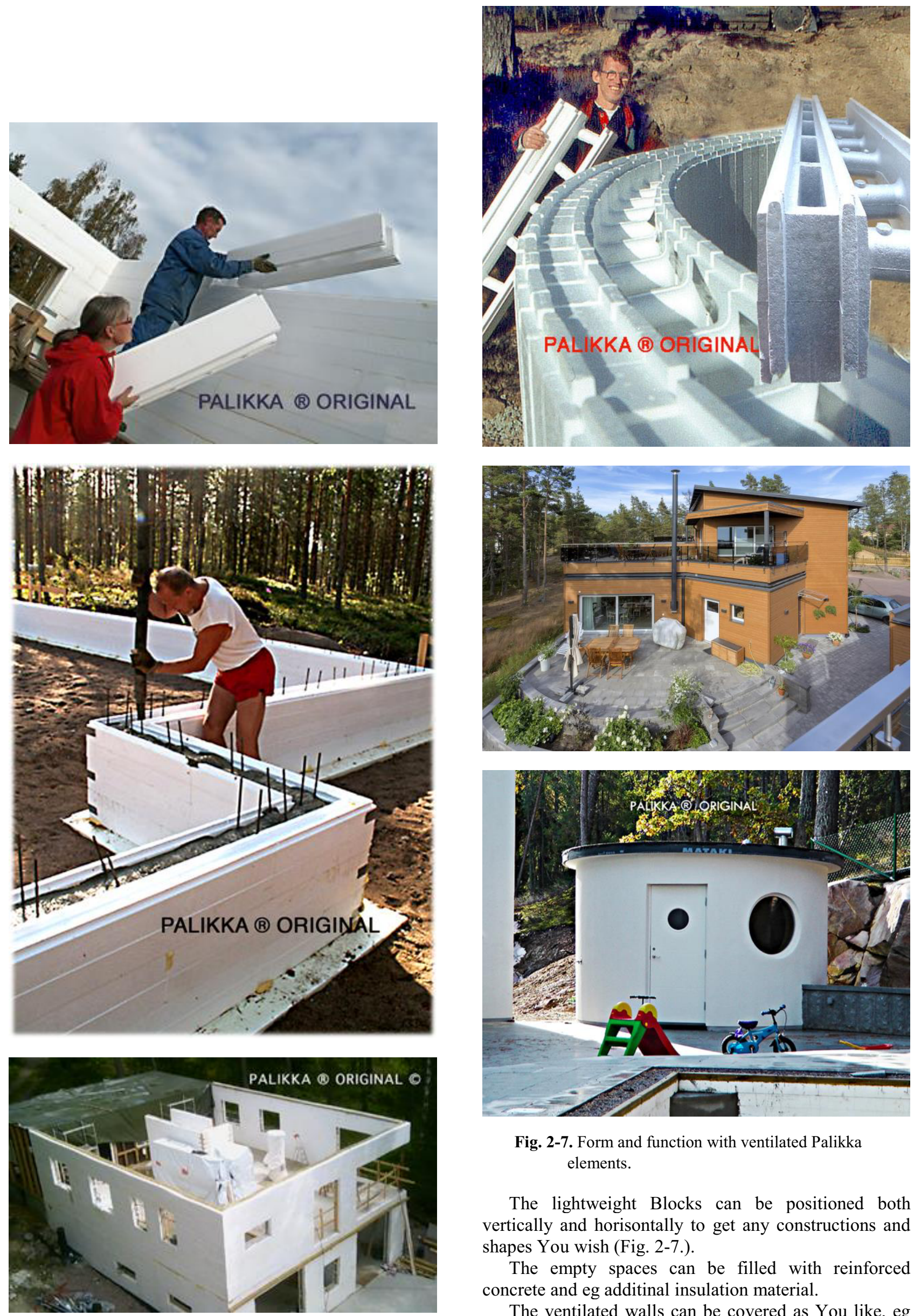

Fig. 2-7. Form and function with ventilated Palikka elements.

The lightweight Blocks can be positioned both vertically and horisontally to get any constructions and shapes You wish (Fig. 2-7.).

The empty spaces can be filled with reinforced concrete and eg additinal insulation material.

The ventilated walls can be covered as You like, eg plastered or clad with wooden panelling etc 
Buildings of any shapes from 2 stories below ground up to 5 stories above ground have been built

Functioning well for already already 50 years, and with good experiences in many countries, Palikka is still the only naturally ventilated Building System, enabling sound and safe energy saving buildings / passive houses without additional costs. The construction is airtight with a tightness of down to 0,2 when 0,6 is sufficient for a good passivehouse.

\section{The Unique Ventilation System}

The Palikka Building Block is made of foodgrade expanded polystyrene without any harmful additives. The Blocks of strong EPS withstand the filling with concrete. The EPS of optimal density does not soak water. The water absorbtion is less than $50 \%$ (Table 1.). The built-in Ventilation System keeps the constructions dry and sound without any mildew problems.

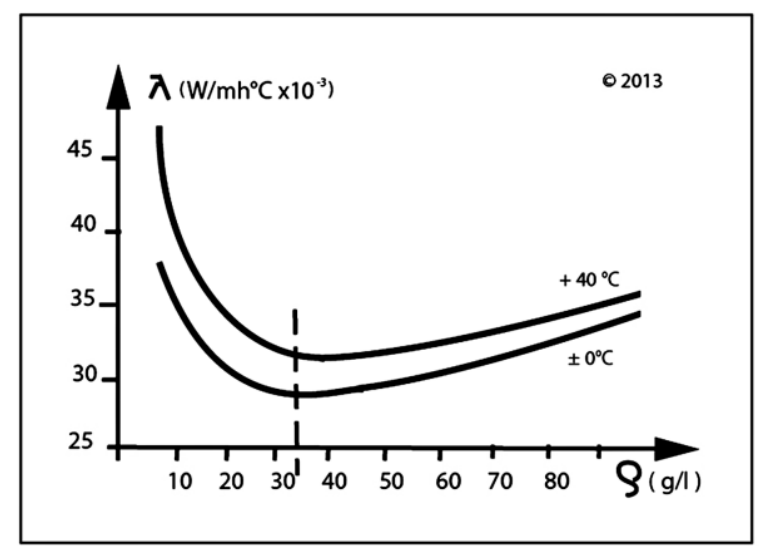

Table 1. Optimal thermal insulation.

The Palikka Blocks have an optimal thermal insulation, which improves as the outdoor temperature goes down.

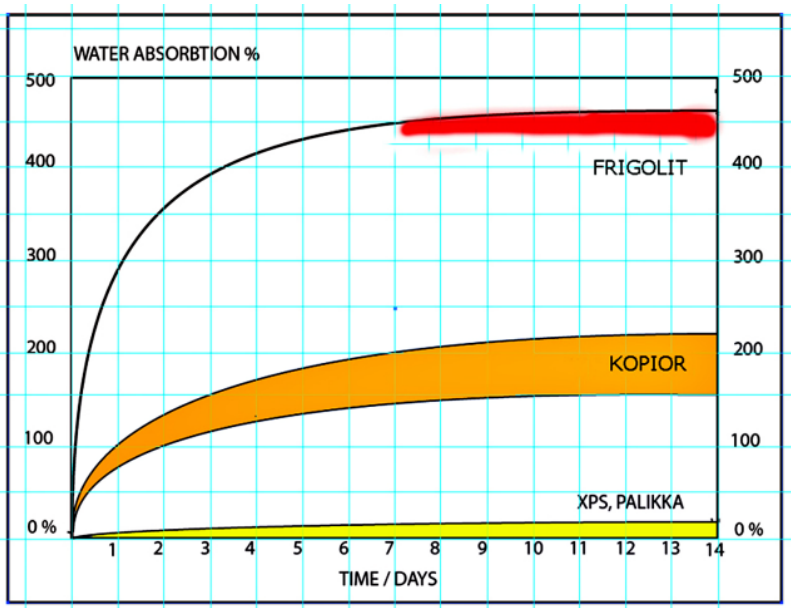

Table 2. Water absorption of EPS products. Palikka Blocks have a very low water absorbtion in comparison with ordinary EPS insulation and ICF copies.

In comparison, other ICF blocks soak up to $200 \%$ water, which means that such walls can contain up to 15 litres of water per m2. Already much smaller amounts of moisture and water cause moisture problems like mildew and the plaster peeling off non-ventilated constructions (Table 2.).

The ventilated Palikka Block consists of 3 interconnected plates with hollow sections in between.

In the building process one cavity is filled with steel reinforced concrete, functioning as the load bearing construction. Buildings up to 5 storeys above and 2 storeys below the ground have been built.

The specially designed outer hollow section functions as the ventilating system of the construction.

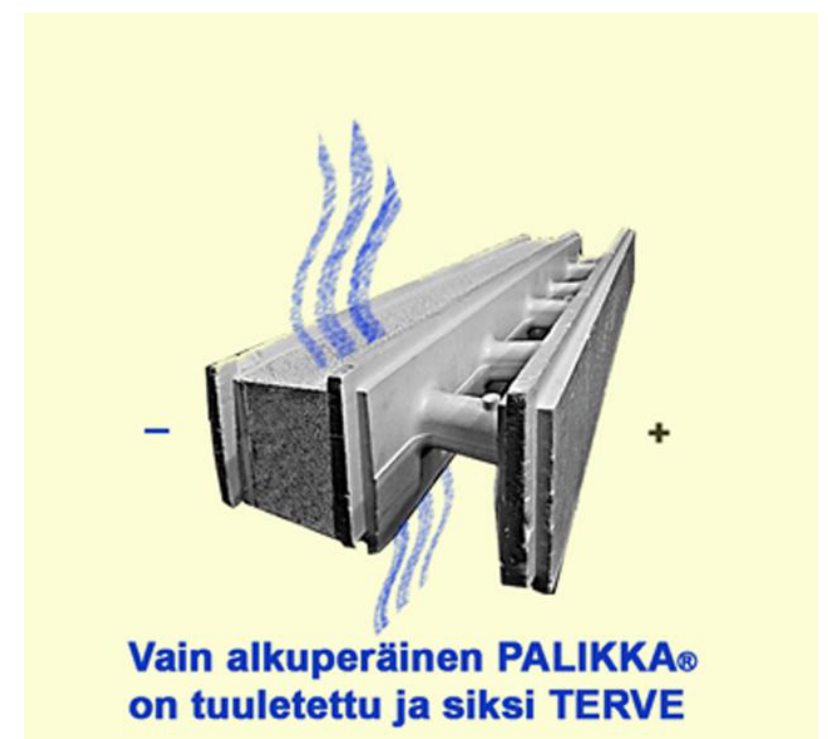

Fig. 8. Ventilation system in work. The Ventilation System dries the constructions quickly and keep the low energy buildings dry and safe without mildew.

The complete Palikka wall is thus ventilated both horizontally and vertically keeping the whole construction dry and sound both below ground and above ground. Below ground no additional ventilation constructions are needed to keep the basement dry, just a PE-foil towards the ground is sufficient as a waterbarrier (Fig. 8.).

As air is a very good thermal insulator, also the air in the ventilation system improves the thermal properties of the wall. The U-value can be chosen $0,22-0,10$ depending on requirements.

Equally important for a building are the windows and the Active ${ }^{\circledR}$ windows enable U-values down to 0,2 .

There is no hurricane blowing in the Ventilation System. The moist air just slowly rises up to the top of the walls, where the moisture is ventilated out and replaced with dry air.

The plastering attaches well to the dry surfaces of the wall. But the plaster effectively prevents the moisture from evaporating from a wall which lacks the important 
ventilation. A moist wall cannot be plastered, as the plaster will peel off, when it freezes in the winter.

A ventilated dry wall can also safely be clad with wooden panelling without the risk of long term moisture damages.

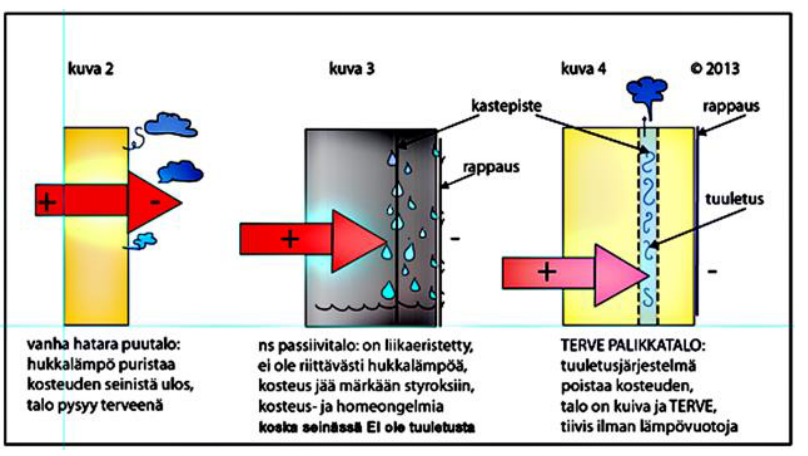

Fig. 9. Comparison of walls with and without ventilation:

2. Older wooden houses with lower thermal insulation have a high energyloss. As they are not tight the

warm indoor air is escaping directly through the walls and they stay dry.

3. In diffusion open and too well insulated ICF walls the moisture is condensating in the dew point.

Because of the

leads to problems, like

off of the plastering in the winter.

4. In constructions with the only Ventilated System the dew point is situated inside the Ventilation

System and out from the

buildings dry and sound

moisture problems, with already 50 years of the moisture is thus safely ventilated constructions keeping the without any

experience.

Moisture and water come into the building materials and the constructions already with rain and snow during the transportation and outdoor storage of the materials, and after that when erecting the buildings outdoor without coverage.

The filling with concrete totally immerses ordinary diffusion open ICF walls with water, that they can soak up to more than $200 \%$. However, the Palikka construction absorbs much less than $50 \%$ water, and in addition the effective Ventilation System controls the drying process of the whole construction (Fig. 9.).

Normal living in the houses also generate moisture for a very long period: cooking, sauna bathing, indoor pools, drying of washes etc produce a lot of moisture. If not ventilated away the moisture will cause problems in the constructions. The Palikka construction is naturally ventilated.

\subsection{Cooling of ventilation air}

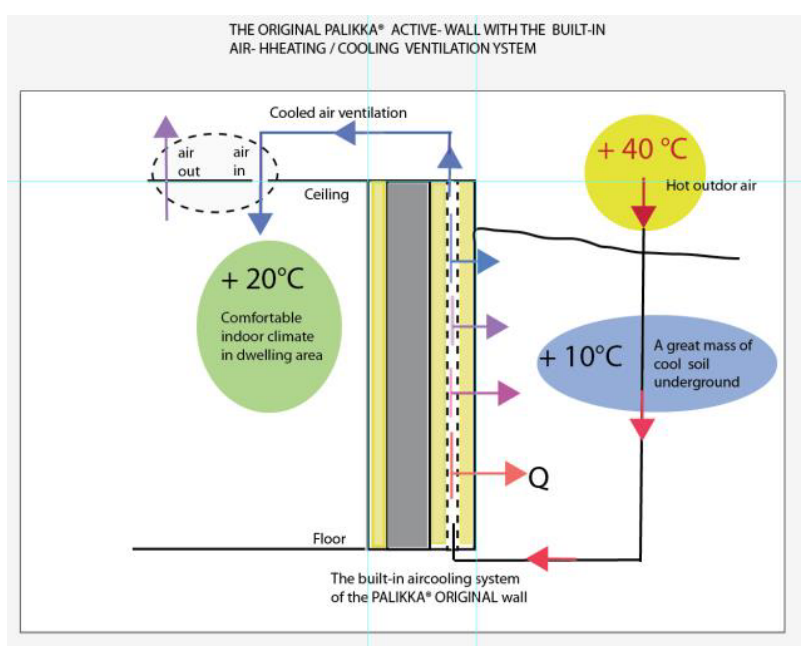

Fig. 10. Schematic function of the Palikka cooling system. The Ventilation System functioning as a heat exchanger, cooling the warm outdoor

air using the of the mass of the much lower temperature ground.

The ventilated walls can also be used for preheating as well as for precooling of the air in the ventilation system of the dwelling areas of the buildings.

The temperature of the mass of the ground in Finland is constantly abt $+4{ }^{\circ} \mathrm{C}$, but the outdoor temperature varies $+30 \ldots-55^{\circ} \mathrm{C}$.

In warmer countries the need for cooling is even bigger. The global warming of the climate also makes cooling a more important issue.

The ground is a vast accumulator of thermal energy, which can be used free of charge.

The ventilated underground walls of a Palikka basement can thus be used as a big temperature exchanger for the ventilation air with a surface area of eg $100 \mathrm{~m} 2$ or more. The filtered warm/ hot outdoor air is lead through the ventilation system of the basement wall with an adjustable speed, depending of cooling needs.

The outdoor air is cooled by the low temperature of the ground and then lead either directly into the dwelling areas or to the ventilation system of the building via heat exchangers, thus cooling the indoor temperature to a pleasant level, without using any extra energy. The cooling principle is shown in the picture showing a hotter climate (Fig. 10.).

For the calculations of the volume per time unit (X $\mathrm{m} 3 / \mathrm{h})$ of preheated air of desired temperature eg $(\mathrm{T} 3=$ $+2 \mathrm{C})$.

It is possible to get into the heatexchagers/ ventilation system/ rooms eg the data given here, with an outdoor air temperature of eg $\left(\mathrm{T} 1=-20^{\circ} \mathrm{C}\right)$ and the ground temperature constantly $\left(\mathrm{T} 2=+4^{\circ} \mathrm{C}\right)$ and a heat exchanging surface of the underground basement walls eg $(A=10 \mathrm{~m} 2)$ with a thickness of $(\mathrm{s}=5 \mathrm{~cm})$ and a Lambda value of 0,033 . 


\subsection{Preheating of ventilation air}

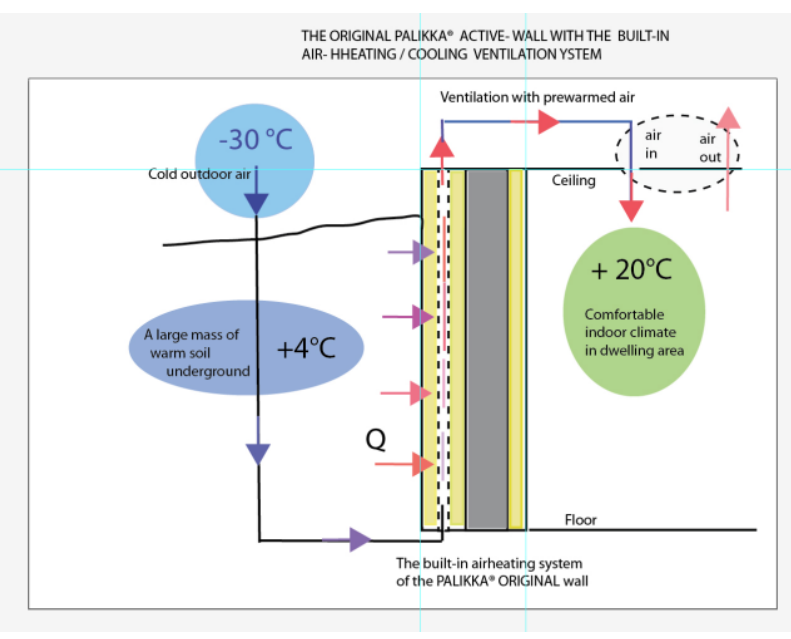

Fig. 11. Principle of the Palikka warming system. Cold outdoor air is led into the Ventilation System, where it is $\quad$ warmed by the heat exchanger taking
energy from the
warmer practically infinite mass of the ground.

When the oudoor temperature is lower than the desired indoor tempertaure the Ventilation System works the opposite way, warming the air without extra costs. During the winter the outdoor temperatures can go down to $-30^{\circ} \mathrm{C}$ or lower, even record tempertaures of $-55^{\circ} \mathrm{C}$ in northern Finland.

A good thermal insulation of the buildings is important for a pleasant living and for minimizing the heating costs.

Preheating of the cold outdoor air for ventilation is easily made using the built in Palikka Ventilation System (Fig. 11.).

The cold outdoor air is filtered and lead into the Ventilation System, where it is warmed by the higher temperature of the $+4^{\circ} \mathrm{C}$ mass of the ground. The temperature of the incoming air is adjusted by the speed of the air being warmed through the thin wallplate towards the warmer ground.

The available capacity of the thermal energy in the ground is unlimited, thus no extra preheating energy is needed in a well insulated energysaving bulding. Depending on the heat transferring area of the wall, the ventilation efficiency maybe is not enough in extreme cases, which depends on the outdoor temperature, the heat exchange area and quantity of air.

The prehetaed air can be lead directly into the rooms because Palikka is made of odourless food grade quality, without any poisonous or harmful additives evaporating into the air.

The preheated air can alternatively be used via heat exchangers by the ordinary ventilation system of the buildings to give extra energy free of charge.
Concrete, steel and plastics do not rotten, they have a long lifespan and are easily recirculated into new high quality products, thus lessening carbon emissions through lower heating/ cooling costs.

With the globally warming climate, the importance of using sustainable and moisture resistant building materials like concrete and plastics with an extended lifecycle of 500 years is becoming more important, as well as an effective ventilation of the constructions to keep them dry and sound. The naturally functioning Ventilation System also keeps the tempertaure of the dwellings at the desired level - not too hot, not too cold.

More info in the list of litterature below:

\section{Birger E. Wasenius}

M.Sc, Eur.Eng

Inventor of the Palikka Building Block and the Building System palikka@palikka.eu

Homepages:

www.palikka.eu, www.palikka.fi, www.palikka.se, www.palikka.ax, www.palikka.ee, www.palikka.de, www.palikkatalo.fi etc Facebook: Palikka Original

Youtube videos and Google pictures are found using the searchword "Palikka Original"

\section{References}

1. Rakennustaito 1975 , Solupolystyreenin ominaisuudet, pp 13-15, Birger Wasenius

2. RT-datacard G(22)-30705,1981,Rakennustietosäätiö

3. RT -datacard E 33504, 1990, Rakennustietosäätiö

4. Muovit rakentamisessa, RIL- 127, ISBN: 951-758-046-0, 1986, Birger Wasenius

5. Byggnadskalendern 1992, pp 1037 -1053, Birger Wasenius

6. PROFI -datacards, continually updated -2020 , PALIKKA Oy

7. PALIKKA productbroschures 1970-2020

8. TM Rakennusmaailma 4/2015, pp 38-41, Henrik Weckström 
9. Hundreds of articles in Rakennussanomat and other building magazines since the 1970s

10. Palikka soundinsulation measurements and reports

11. Palikka firetest reports

12. CE -conformity statement 